\title{
Changes in the Work Environment for Creativity During Downsizing
}

\section{Citation}

Amabile, T. M., and R. Conti. 1999. "Changes in the Work Environment for Creativity During Downsizing." Academy of Management Journal 42 (6): 630-40. https://doi.org/10.2307/256984.

\section{Permanent link}

http://nrs.harvard.edu/urn-3:HUL.InstRepos:37940231

\section{Terms of Use}

This article was downloaded from Harvard University's DASH repository, and is made available under the terms and conditions applicable to Other Posted Material, as set forth at http:// nrs.harvard.edu/urn-3:HUL.InstRepos:dash.current.terms-of-use\#LAA

\section{Share Your Story}

The Harvard community has made this article openly available.

Please share how this access benefits you. Submit a story.

\section{Accessibility}




\title{
CHANGES IN THE WORK ENVIRONMENT FOR CREATIVITY DURING DOWNSIZING
}

\author{
TERESA M. AMABILE \\ Harvard University \\ REGINA CONTI \\ Colgate University
}

\begin{abstract}
This study examined the work environment for creativity at a large high-technology firm before, during, and after a major downsizing. Creativity and most creativitysupporting aspects of the perceived work environment declined significantly during the downsizing but increased modestly later; the opposite pattern was observed for creativity-undermining aspects. Stimulants and obstacles to creativity in the work environment mediated the effects of downsizing. These results suggest ways in which theories of organizational creativity can be expanded and ways in which the negative effects of downsizing might be avoided or alleviated.
\end{abstract}

\begin{abstract}
A downsizing such as this one is always difficult for employees. But out of tough times can come strength, creativity and teamwork. [We are] fortunate to retain committed, hard-working and creative employees, who will find substantial motivation and fulfillment as we all work together in 1995 to achieve [our] turnaround. (From the letter to shareholders in the 1994 annual report of a United States software company)

Our strategy is to reduce operating costs to a level commensurate with projected sales levels. To accomplish this goal, we have implemented a number of tough cost-cutting measures, which include downsizing of the workforce, facilities and other operating costs. In addition to cutting costs, we are focusing on product innovation through our highly effective Research and Development team. (From the letter to shareholders in the 1996 annual report of an international electronic games company)
\end{abstract}

American companies continued to downsize their workforces through most of the 1990s, but

The data for this study were collected when both authors were in the Department of Psychology at Brandeis University. The data collection and analysis were supported by a grant from the Center for Innovation Management Studies at Lehigh University. We are most grateful to the Center and its corporate sponsors for their support. Preparation of this article was supported by the Harvard Business School Division of Research. We wish to acknowledge Jill Nemiro and Thomas Leahy for their highly competent work as interviewers. We also wish to express our appreciation to the managers and employees of the company studied, especially certain individuals in the organizational research department, for the crucial roles they played in the collection of the data reported here. they also continued to emphasize the importance of innovation to long-term success. Do the two goals go hand-in-hand, as these letters to shareholders suggest, or are they incompatible?

As noted by McKinley and his colleagues (McKinley, 1993; Mone, McKinley, \& Barker, 1998), there is considerable controversy among theoreticians about the effects of downsizing on a variety of organizational outcomes, including innovation. Most scholars have adopted a definition of downsizing similar to that of Freeman and Cameron (1993), describing it as an intentional management action involving a reduction in force and designed to improve a company's competitive position. Some theorists have taken the viewpoint expressed in the first letter to shareholders quoted earlier, arguing that a reduction in force will have generally positive effects on a company's efficiency, reducing waste and leading to a more productive allocation of resources (e.g., Jensen, 1986). However, othersmost notably Cascio (1993)- have suggested that innovation will be likely to suffer during downsizing.

Innovation, generally defined as the implementation or adoption of new, useful ideas by people in organizations (Amabile, 1988, 1996; Van de Ven, 1986), depends on creativity-the generation of those new and useful ideas (Amabile, 1983a, Amabile, 1983b). This article focuses on creativity and, in particular, changes in the work environment for creativity during downsizing.

If indeed creativity is dampened during downsizing, the work environment may play a central role in this decline. In a theoretical model of the effects of layoffs on survivors, Brockner (1988) highlighted the importance of the work environ- 
ment, which he referred to as context. Context encompasses all elements of the psychological climate of both the formal organization (policies and procedures) and the informal organization (values, norms, and interpersonal relationships). Brockner's research has shown that context can be important not only in affecting survivors' reactions to layoffs, but also in determining the impact of those reactions on job performance and other outcomes (e.g., Brockner, Davy, \& Carter, 1985; Brockner, Greenberg, Brockner, Bortz, Davy, \& Carter, 1986; Brockner, Grover, Reed, DeWitt, \& O'Malley, 1987; Brockner, Wiesenfeld, Reed, Grover, \& Martin, 1993).

Previous research has uncovered some common patterns of change in organizational work environments during downsizing. Organizations appear to undergo a deterioration of communication at many levels (Cascio, 1993; Dougherty \& Bowman, 1995; Noer, 1993) during such periods, even though communication appears to be particularly important at these times (Rosenblatt, Rogers, \& Nord, 1993). Similarly, downsizing organizations appear to suffer a deterioration of trust (Buch \& Aldridge, 1991; Cascio, 1993) and an increase in fear (Buch et al., 1991). Organizations in decline (which include most organizations undergoing downsizing) are marked by a resistance to change and a tendency toward rigid behavior patterns (Cameron, Sutton, \& Whetton, 1988). Finally, the work environments of downsizing organizations appear to be marked by high levels of uncertainty and chaos (Tombaugh \& White, 1990).

How might such changes in the work environment come about? Threat-rigidity theory (Staw, Sandelands, \& Dutton, 1981) directly addresses possible changes in organizational environments under negative circumstances such as those accompanying downsizing. The theory is concerned with situations of threat, defined as an external event or circumstance in which individuals, groups, or organizations perceive impending negative or harmful consequences for their vital interests. Clearly, this definition applies to most organizations that undertake downsizing; it certainly applies to the organization examined in the present study. Although threat is proposed to have conceptually similar effects on individuals, groups, and organizations, it is threat-rigidity theory's organizational level of analysis that is most relevant to a consideration of changes in work environments during downsizing.

According to this theory, under threatening conditions, organizations undergo a "mechanistic shift" (Staw et al., 1981: 516). They centralize control, conserve resources, restrict information flow, and rely on familiar, well-practiced routines. Under some conditions, when the organizational threat arises from relatively small, incremental changes, such effects can be useful. However, threat-rigidity theory implies that, under the types of radical changes that are likely to precede or accompany downsizing, the resulting effects will be dysfunctional. This position has received considerable empirical support, primarily from studies of organizational crisis (e.g., Billings, Milburn, \& Shaalman, 1980; D'Aveni \& MacMillan, 1990; Smart \& Vertinsky, 1984; Tjosvold, 1984) and studies of centralization, efficiency, and resistance to change (e.g., Cameron, Whetten, \& Kim, 1987; D'Aveni, 1989; Whetten, 1981).

Recent theories of organizational creativity stress the role of an organization's work environment in affecting creative behaviors of individuals and teams (Amabile, 1988; Woodman, Sawyer, \& Griffin, 1993). According to the componential model of creativity and innovation in organizations (Amabile, 1988, 1997; Amabile, Conti, Coon, Lazenby, \& Herron, 1996), five environmental components affect creativity: encouragement of creativity (which encompasses open information flow and support for new ideas at all levels of the organization, from top management, through immediate supervisors, to work groups); autonomy or freedom (autonomy in the day-to-day conduct of work; a sense of individual ownership of and control over work); resources (the materials, information, and general resources available for work); pressures (including both positive challenge and negative workload pressure); and organizational impediments to creativity (including conservatism and internal strife). As measured by the survey instrument KEYS: Assessing the Climate for Creativity (Amabile, 1996), the components fall into two general categories: stimulants to creativity (tapped by scales assessing organizational and supervisory encouragement, work group support, sufficient resources, and challenging work), and obstacles to creativity (tapped by scales assessing organizational impediments and workload pressure). In a study in a high-tech company (Amabile et al., 1996), $R \& D$ projects rated high in creativity had significantly different work environments (as measured by KEYS) from those projects rated low in creativity. The high-creativity projects were generally higher on work environment stimulants to creativity and lower on work environment obstacles to creativity. Thus, it appears that there is indeed a relationship between the work environment and the level of creativity produced by individuals in teams.

The mechanistic shift described in threat-rigidity 
theory suggests consequential changes during downsizing in the aspects of the work environment that have been identified as important for creativity. Previous research on change in organizations undergoing downsizing, described above, also points to changes in creativity-relevant aspects of the work environment. Moreover, there is some evidence that creativity itself may decline during downsizing. Cascio (1993) concluded that downsizing survivors become narrow-minded and risk-averse. Other researchers have found evidence that members of organizations in decline exhibit a tendency toward rigid behavior patterns (Cameron et al., 1988). Given that risk-taking and flexibility in behavior are central to the generation of creative ideas, this evidence suggests that downsizing survivors will indeed be less creative in their work. The present study examined three hypotheses relevant to these proposed changes in work environments, and in creativity, as a function of downsizing.

\section{Hypothesis 1. Creativity will decrease as a} function of downsizing.

Hypothesis 2. The relationship between creativity and downsizing will be accounted for by decreases in work environment stimulants to creativity and increases in work environment obstacles to creativity.

\section{METHODS}

\section{Design Overview}

This study examined the work environment for creativity in a large high-technology firm before, during, and after a major downsizing. We assessed work environment and creativity by sampling independent groups of surviving employees at four points in time: baseline (predownsizing), wave 1 (middownsizing), wave 2 (official end of downsizing), and wave 3 (postdownsizing). Measures of downsizing were taken at three points in time: wave 1 , wave 2 , and wave 3 . For exploratory purposes, we included a number of other measures and conducted semistructured interviews with survivors.

Some individuals in this company experienced considerable downsizing in their departments, some were spared, and a few actually experienced growth in their departments during the period studied. Therefore, the design allowed for examination of perceived work environment and various other outcomes as a function of the degree and type of downsizing change experienced. Downsizing was operationally defined through three measures of changes experienced by individuals in the organization; each of these changes is a common ac- companiment of a downsizing of one's department or work group: recently experienced downsizing in one's own department (downsizing experienced), anticipation of future downsizing in one's own department (anticipated downsizing), and recent disruption of the stability of one's own work group (work group stability).

\section{Research Setting}

This study was conducted in a Fortune 500 hightechnology company with over 30,000 employees that provided diversified electronics products to international markets. In the course of conducting an earlier study, we had obtained work environment assessments from a broad sample of the company's employees in January 1993. Approximately four months later, the chairman of the company announced that a major restructuring of the company was necessitated by disappointing corporate profitability and by a radical shift in the company's major market. Employees were told that the restructuring would be accompanied by downsizing the workforce by 12-15 percent. Additionally, they were told that this reduction in force was to be accomplished by successive waves of early retirement incentives, voluntary separation incentives, and involuntary layoffs. There was no announced standard procedure for determining layoffs.

In addition to the predownsizing baseline data collected in January 1993, we collected data in July 1994 (wave 1), when the downsizing was at about 60 percent of its stated target; in December 1994 (wave 2), just as the downsizing was reaching its previously announced completion; and in May 1995 (wave 3).

Each wave of data collection targeted a different random sample of employees. This betweensubjects design was necessary because the company required that all questionnaires be anonymous, and because sample attrition due to employees leaving the company (either voluntarily or involuntarily) during the downsizing would have made it impossible for us to follow one group of people through all waves.

\section{Respondents}

A total of 754 employees participated in the study. There were 455 respondents to the baseline data collection (a 45.5 percent response rate); 102 at wave $1(34 \%) ; 87$ at wave $2(29 \%)$; and 110 at wave $3(37 \%)$. At waves 1,2 , and 3 , respondents were asked to volunteer for interviews, and 83 were subsequently interviewed: 34 at wave 1,23 at wave 2 , and 26 at wave 3 . 
These volunteers were interviewed in 20-minute sessions either in person or via telephone, by one of four interviewers. To avoid biasing responses, the interviewers used the more neutral term "restructuring" rather than "downsizing." The questions focused on changes experienced during the restructuring, perceptions of various aspects of the work environment, general motivational and social changes experienced or observed, and suggestions for management about the restructuring.

\section{Instruments}

Respondents in all phases of data collection completed the work environment survey KEYS: Assessing the Climate for Creativity (Amabile, 1995; Amabile, Burnside, \& Gryskiewicz, 1995; Amabile \& Gryskiewicz, 1989). In addition, respondents for waves 1,2 , and 3 completed a background questionnaire.

KEYS: Assessing the Climate for Creativity. The KEYS instrument is designed to assess factors in the work environment that influence creativity and innovation, according to previous theory and research (see Amabile, 1988, 1996). KEYS includes eight work environment scales (six stimulants to creativity and two obstacles to creativity) and two criterion scales (creativity and productivity). The 78-item inventory asks respondents to indicate the extent to which each statement describes their work environment. Thus, the instrument assesses respondents' perceptions of specific stimulants and obstacles to creativity, as well as their perceptions of the actual creativity and productivity of the work being done (the criterion scales). KEYS has been shown to have satisfactory psychometric properties, in terms of both reliability and validity (Amabile et al., 1996).

The six stimulants to creativity scales, listed here with the major concepts they cover summarized in parentheses, are (1) organizational encouragement (15 items, Cronbach's alpha $[\alpha]=.92$; an organizational culture that encourages creativity through an active flow of ideas, the fair and constructive judgment of ideas, reward and recognition for creative work, mechanisms for developing new ideas, and a shared vision of what the organization is trying to do); (2) sufficient resources ( 6 items, $\alpha=.82$; access to appropriate resources, including funds, materials, facilities, and information); (3) freedom (4 items, $\alpha=.69$; freedom in deciding what work to do or how to do it; a sense of control over one's work); (4) challenging work ( 5 items, $\alpha=.80$; a sense of having to work hard on challenging tasks and important projects); (5) supervisory encouragement (11 items, $\alpha=.92$; a supervisor who commu- nicates effectively with the work group, serves as a good work model, sets goals appropriately, supports the work group, values individual contributions, and shows confidence in the work group); and (6) work group supports ( 8 items, $\alpha=.86$; a diversely skilled work group in which people communicate well, are open to new ideas, constructively challenge each other's ideas, trust and help each other, and feel committed to the work they are doing).

The two KEYS obstacles to creativity scales (again, listed with major concepts) are: (1) organizational impediments ( 12 items, $\alpha=.84$; an organizational culture that impedes creativity through internal political problems, harsh criticism of new ideas, destructive internal competition, an avoidance of risk, and an overemphasis on the status quo) and (2) workload pressure (5 items, $\alpha=.77$; extreme time pressures, unrealistic expectations for productivity, and distractions from creative work).

The two KEYS criterion scales (listed with major concepts) are: (1) creativity (6 items, $\alpha=.84$; a creative and innovative organization or unit, where a great deal of creativity is called for and where people believe they actually produce creative work) and (2) productivity ( 6 items, $\alpha=.88$; an efficient, effective, and productive organization or unit).

Background questionnaire. This questionnaire, created for the present study, obtained measures of changes experienced and anticipated during the downsizing, including (1) respondents' numerical estimates of the percent changes in the sizes of their departments since the last data collection (downsizing experienced), (2) the anticipated percent changes in the sizes of their departments over the next year (anticipated downsizing), and (3) changes in the membership of their work groups since the last data collection (work group stability/disruption). The questionnaire also included a number of other exploratory measures, such as self-reported risk-taking and entrepreneurialism, perceived uncertainty and chaos, job satisfaction, morale, feelings, and likelihood of voluntary exit. The questions on the background questionnaire were derived in part from the existing literature on the effects of downsizing on employees (see Cascio, 1993).

\section{RESULTS}

\section{Downsizing}

Table 1 presents data on the reported downsizing changes. (Recall that comparable data were not collected at the baseline point, although the wave 1 
TABLE 1

Downsizing Changes ${ }^{\mathrm{a}}$

\begin{tabular}{|c|c|c|c|}
\hline Variable & Wave 1 & Wave 2 & Wave 3 \\
\hline Percent change in size of department since previous data collection ${ }^{b}$ & $-13.66_{a}(32.70)$ & $-3.68_{\mathrm{b}}(35.25)$ & $-6.11_{b}(29.86)$ \\
\hline Anticipated percent change in department size in next year ${ }^{\mathrm{c}}$ & $-17.03_{\mathrm{a}}(30.45)$ & $-0.06_{b}(39.27)$ & $-2.90_{b}(36.36)$ \\
\hline Multivariate $F_{10.520}$ & \multicolumn{2}{|c|}{$4.40^{\star \star *}$} & \\
\hline
\end{tabular}

"Values shown are means and standard deviations (in parentheses). Means with different subscripts ("a" or "b") are significantly different $(p<.05)$ as revealed by contrasts.

b The overall effect was significant at $p<.05$.

c The overall effect was significant at $p<.01$.

$\mathrm{d}$ The overall effect was significant at $p<.001$.

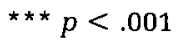

questionnaire did ask for reports of changes experienced since the baseline data collection.) These measures include the reported change in the size of a respondent's department occurring since the previous data collection (as the percent smaller or larger), the reported anticipated change in department size in the upcoming year (as the percent smaller or larger), and the reported stability in the membership of the respondent's work group (an average of three items, $\alpha=.74$, asking about the percentage of previous coworkers whom the respondent was still working with; a higher number signifies greater stability). These results confirm that a large downsizing was experienced by the respondents between the baseline and wave 1 data collections and that stability increased thereafter.

\section{Changes in Creativity}

A multivariate analysis of variance (MANOVA) comparing the criterion scales from the baseline, wave 1 , wave 2 , and wave 3 showed a significant multivariate effect and significant univariate ef- fects for both the creativity and productivity scales (see Table 2). Univariate contrasts for creativity showed that it was significantly below baseline levels at all three later time points. Productivity was significantly below baseline at waves 1 and 2, but not at wave 3 . Thus, Hypothesis 1 is supported: it appears that creativity did decline during the downsizing. Notably, changes in employees' assessments of creativity were much greater and more enduring than were changes in their assessments of productivity.

To obtain an additional and more objective measure of creativity and innovation, we attempted to secure month-by-month information on the number of invention disclosures and patent applications at the company for the years before, during, and after the downsizing announcement. Unfortunately, we were able to obtain only data aggregated by year for two of those years (the year during which the downsizing started in August and the following year, when the downsizing ended in December); thus, this information is only suggestive. The number of

TABLE 2

Creativity and Productivity ${ }^{\mathrm{a}}$

\begin{tabular}{|c|c|c|c|c|}
\hline KEYS Criterion Scale ${ }^{b}$ & $\begin{array}{c}\text { Baseline, } \\
\text { January } 1993\end{array}$ & $\begin{array}{l}\text { Wave 1, } \\
\text { July } 1994\end{array}$ & $\begin{array}{c}\text { Wave 2, } \\
\text { December } 1994\end{array}$ & $\begin{array}{c}\text { Wave 3, } \\
\text { May } 1995\end{array}$ \\
\hline $\begin{array}{l}\text { Creativity }^{c} \\
\text { Productivity }^{\mathrm{d}}\end{array}$ & $2.73(0.65)$ & $2.35_{a}(0.63)$ & $2.49_{\mathrm{a}}(0.56)$ & $2.54_{\mathrm{a}}(0.65)$ \\
\hline
\end{tabular}

Multivariate $F_{6,1510}$

$6.62^{* * *}$

a Values shown are means and standard deviations (in parentheses). Means with the subscript "a" were significantly different from the baseline measure $(p<.05)$ in a contrast test. For the four data collections, $n=455,102$, 87, and 110 , respectively.

b The KEYS response scale ranges from 1, "never or almost never true of your current work environment," to 4, "always or almost always true of your current work environment."

"The overall effect was significant at $p<.001$.

$\mathrm{d}$ The overall effect was significant at $p<.01$.

${ }^{\star * *} p<.001$ 
employees decreased by 15 percent from the year during which the downsizing started through the year during which it ended, and the number of patent applications declined by about the same amount $(12 \%)$. These percentages indicate that the number of patent applications per employee remained approximately constant during the downsizing. However, because of the long process required in submitting patent applications, this indicator of creative activity would be expected to show considerably lagged effects. By contrast, the number of invention disclosures submitted during a given period of time is a more immediate indicator of current technological invention. Importantly, invention disclosure submissions declined by a disproportionate 24 percent during the same period. In other words, per capita, people were producing fewer new ideas. These data provide some additional support for the conclusion that, indeed, declines in creativity accompanied the downsizing.

Although the MANOVA results demonstrated that declines in creativity accompanied downsizing, we also examined Hypothesis 1 more directly by determining the extent to which creativity declined as a function of downsizing. To this end, using data across all postbaseline waves, we re- gressed creativity on each of the three downsizing measures (downsizing experienced, anticipated downsizing, and work group stability). Two of the three measures (anticipated downsizing and work group stability) were significant predictors of creativity, and the overall regression equation was significant $\left(F_{3,288}=4.04, p<.01, R^{2}=.04\right)$.

Many of the interviewees' comments focused on how the downsizing limited creativity; for example, one employee said the following: "Before, creativity wasn't promoted; now it's promoted even less. People feel stifled. They don't take risks because of the ramifications. They're worried about getting laid off." Another interviewee said this: "The quality of our work dropped, because the sense of pride declined. We were no longer really a team. Instead, everyone was trying to protect their job-to justify themselves by looking good. They're not focused on the work itself."

\section{Changes in the Work Environment}

Table 3 presents work environment means on each of the KEYS work environment scales for the baseline and for waves 1,2 , and 3 . Overall, the pattern is quite clear and consistent. All six KEYS environmental stimulants to creativity declined no-

TABLE 3

Work Environment ${ }^{\mathrm{a}}$

\begin{tabular}{|c|c|c|c|c|}
\hline KEYS Scale ${ }^{b}$ & $\begin{array}{c}\text { Baseline, } \\
\text { January } 1993\end{array}$ & $\begin{array}{l}\text { Wave 1, } \\
\text { July } 1994\end{array}$ & $\begin{array}{c}\text { Wave 2, } \\
\text { December } 1994\end{array}$ & $\begin{array}{l}\text { Wave 3, } \\
\text { May } 1995\end{array}$ \\
\hline \multicolumn{5}{|l|}{ Stimulants to creativity } \\
\hline Challenge $^{d}$ & $2.95(0.65)$ & $2.64_{\mathrm{a}}(0.61)$ & $2.72_{\text {a }}(0.64)$ & $2.74_{\mathrm{n}}(0.63)$ \\
\hline Sufficient resources ${ }^{\mathbf{0}}$ & $2.78(0.58)$ & $2.58_{a}(0.57)$ & $2.68 \quad(0.61)$ & $2.89_{b}(0.53)$ \\
\hline Supervisory encouragement & $2.83(0.73)$ & $2.70_{b}(0.60)$ & $2.74(0.68)$ & $2.85(0.71)$ \\
\hline Multivariate $F_{18,2,118}$ & \multicolumn{2}{|c|}{$4.87^{\star \star *}$} & & \\
\hline \multicolumn{5}{|l|}{ Obstacles to creativity } \\
\hline Organizational impediments ${ }^{\circ}$ & $2.25(0.59)$ & $2.44_{a}(0.56)$ & $2.27(0.54)$ & $2.18 \quad(0.51)$ \\
\hline Workload pressures $^{\circ}$ & $2.59(0.61)$ & $2.61(0.63)$ & $2.55(0.56)$ & $2.37_{\mathrm{a}}(0.57)$ \\
\hline
\end{tabular}

a Values shown are means and standard deviations (in parentheses). Means with the subscript "a" were significantly different ( $p<.05$ ) from the baseline measure in a contrast test. The subscript " $b$ " indicates marginal difference $(p<.10)$ from the baseline. For the four data collections, $n=455,102,87$, and 110 , respectively.

b The KEYS response scale ranges from 1, "never or almost never true of your current work environment," to 4, "always or almost always true of your current work environment." The reliabilities of the KEYS scales in this study were comparable to those published in the literature (Amabile et al., 1996). The median alphas were .88 for the baseline, .86 for wave $1, .85$ for wave 2 , and .85 for wave 3 .

c The overall effect was significant at $p<.05$.

d The overall effect was significant at $p<.001$.

' The overall effect was significant at $p<.01$.

$\star \star p<.01$

$\star * * p<.001$ 
tably from the baseline to wave 1 . In contrast, the KEYS obstacle measure, organizational impediments, increased. These results support the $\mathrm{Hy}$ pothesis 2 prediction that, during downsizing, work environment stimuiants to creativity will decrease and work environment obstacles will increase. The trend seems to be slowly reversing, however, as one moves from wave 1 to waves 2 and 3 ; the creativity stimulants are increasing, and organizational impediments are declining. MANOVAs followed by univariate analyses of variance and simple contrasts confirmed these patterns (see Table 3). Interestingly, although two aspects of the work environment showed a significant improvement at wave 3 (there was a higher level of sufficient resources and a lower level of workload pressure), two other aspects (challenge and work group supports) showed a continuing significant depression of the work environment for creativity even five months after the downsizing ended.

The interviewees' comments largely reinforced the view that the work environment deteriorated during the downsizing. For example, several commented on supervisor support; one interviewee stated this: "Supervisory support? None, zero-has gone from bad to worse. ... They're in limbo too." Many described structural changes relating to uncertainty and chaos: "During and after the restructuring, there was frustration at the chaos of who moved into where, and what the new structure looked like. I no longer knew where to go to do what I needed to do. Many people had no idea where they themselves were in the new organization." About an equal number of respondents mentioned social changes; often, these changes interfered with unit functioning: "The impact has been negative, in all respects. Communication is not as open and honest. Cooperation is politically based, not oriented toward the customer's benefit. Trust within the group has deteriorated, because people are worried about their jobs." Effects on personal functioning were rarely reported. But when they did occur, the circumstances were quite severe: "I'm very stressed and angry. My ulcer started acting up again recently, after 13 years. I thrive on good stress, but it's all bad now" and "Our place is being shut down ... we've had two suicides here."

Hypothesis 2 suggests that the relationship between downsizing and creativity is mediated (see Judd \& Kenny, 1981) by such changes in the work environment. As noted earlier, two of the three downsizing measures (anticipated downsizing and work group stability) significantly predicted creativity. Additional regression analyses demonstrated that these same downsizing measures predicted both environmental stimulants $\left(F_{3,288}=8.44, p<.001\right)$ and en- vironmental obstacles $\left(F_{3,288}=4.33, p<.01\right)$ to creativity. Furthermore, with the effects of both environmental stimulants $(\beta=.84, t=18.10, p<.001)$ and environmental obstacles $(\beta=.22, t=4.79, p<$ .001 ) on creativity controlled, these downsizing measures no longer significantly predicted creativity $\left(\Delta R^{2}=.01, p>.25\right)$. Thus, the effects of downsizing on creativity appear to be fully mediated by the work environment stimulants and obstacles to creativity.

In all of the regressions involving the downsizing measures, anticipated downsizing and work group stability played a more important role than downsizing experienced. The relative importance of the downsizing measures is highlighted by correlational patterns between those measures and several exploratory measures from the background questionnaire. Experienced departmental downsizing reported by respondents correlated significantly $(p<.05)$ with only four measures: reports of perceived job security $(r=.19)$, morale (self, $r=.14$, and coworkers, $r=.12$ ), and core capability of the unit $(r=.21)$. By contrast, anticipated downsizing correlated significantly with several additional self-reported measures. Respondents who expected greater downsizing in their departments in the coming year reported lower levels of job satisfaction $(r=.17)$, job security $(r=.37)$, morale (self, $r=$ $: 23$, and coworkers, $r=.35$ ), and core capability of the unit $(r=.24)$; they reported higher probabilities of voluntarily taking a job in another company in the same industry $(r=.20)$ and higher probabilities of voluntarily leaving the industry altogether $(r=.26)$.

Respondents whose work groups were less stable were significantly $(p<.05)$ more likely to report higher levels of depression $(r=-.17)$, worry $(r=$ $-.13)$, and guilt $(r=-.20)$, lower levels of happiness $(r=.13)$, and a greater likelihood of leaving the company voluntarily $(r=-.19)$. Moreover, they reported significantly. $(p<.05)$ lower levels of entrepreneurial behavior on their teams $(r=.17)$, less risk-taking $(r=.17)$, lower job satisfaction $(r=.13)$ and morale $(r=.18)$, lower core capability in their units $(r=.16)$, and less focus in their own work $(r=.14)$.

\section{DISCUSSION}

This study suggests that the event of organizational downsizing is accompanied by negative changes in the work environment for creativity along several specific dimensions that have, in previous research (Amabile et al., 1996), been shown to play a particularly important role in project team creativity. As expected, this study also uncovered evidence that creativity itself diminishes during a 
downsizing. Most importantly, however, the mediational analysis revealed that the relationship between downsizing and creativity can be largely accounted for by negative changes in an organization's work environment.

For the first time, a study has tracked the time course of work environment changes that accompany downsizing and has identified varying changes in different aspects of the work environment. Although Noer (1993) suggested that survivors may not recover from the negative effects of downsizing, our data suggest that the perceived work environment does improve to some extent. Perhaps, by wave 3 , some people were beginning to accept the fact of ongoing change within this company, as Noer suggested people must do.

Unfortunately, although productivity and the work environment improved on many dimensions, creativity appeared to have still suffered. considerably, even several months after the downsizing ended. If, indeed, the creativity of individuals and teams continued to be depressed well beyond the end of the downsizing, and well beyond an apparent improvement in several aspects of the work environment, the product innovation future of this high-tech company could be in serious danger.

It is particularly interesting that actually experienced downsizing was a much weaker predictor of perceived work environment than was work group stability or anticipated downsizing; future research should focus particular attention on these aspects of downsizing. The work group stability results are largely consistent with the theory of the need to belong (Baumeister \& Leary, 1995), which suggests that ongoing relational human bonds are a powerful, fundamental, and pervasive motive, having strong positive effects on emotional patterns and cognitive processes. The anticipated downsizing results suggest that, even if an employee's work unit has been decimated, the certainty of knowing that the process is over leads to a generally more positive work environment than the expectation of future downsizing in a currently intact unit. Consistent with affective forecasting theory (Gilbert, Pinel, Wilson, \& Blumberg, 1997), the anticipation of the negative event may be less tolerable than the actual experience.

The results of this study suggest the possibility of adding a dynamic element to the componential model of organizational creativity (Amabile, 1988, 1996). In its current articulation, the componential model is static. It specifies relationships between the perceived work environment and creative behavior at any one point in time. It does not address the dynamics of change in the work environment. It does not specify how events and patterns of events occurring within organizations might lead individuals to perceive their work environments as creativity-supporting or creativity-undermining. What sorts of events give rise to such environments, and what sorts of events lead to change in those environments? If causality can be firmly established in future research, the relationships identified in the present study will begin to point toward an elaboration of the componential model by suggesting one class of events that may prove to have a particularly powerful effect on the work environment for creativity.

One promising avenue of research could be investigation of the mechanisms by which downsizing events, particularly anticipated downsizing and work group instability, might lead to degraded work environments. Threat-rigidity theory (Staw et al., 1981) could be especially helpful in guiding such investigations, because it directly addresses possible changes in organizational environments under negative circumstances such as those accompanying downsizing. Specifically, the following effects could be predicted: (1) a centralization of control would lead to perceptions of lower autonomy/freedom, (2) a conservation of resources would lead to perceptions of less sufficient resources, (3) restriction of information flow would lead to perceptions of less encouragement of creativity from the organization overall (organizational encouragement), from one's own supervisor (supervisory encouragement), and from one's work group (work group supports), and (4) reliance on familiar routines would lead to perceptions of more organizational impediments to creativity, through a generally greater conservatism. Future research testing these predictions derived from threat-rigidity theory could profitably expand the componential model of creativity by providing evidence of specific antecedents to the various work environment factors. Thus, researchers may begin to understand how downsizing and other organizational events bring about change in the perceived work environment for creativity.

Clearly, the conclusions that can be drawn from this study are limited. First, and perhaps most importantly, this study identified relationships, not causes. It is possible that something else was going on, at the same time as the downsizing, that led to some or all of the changes noted. For example, there may have been changes in the employee population from which we drew our four random samples, owing to the layoffs and resignations. Respondents for the four waves of data collection may have used different frames of reference to complete 
the surveys. However, given that our results are consistent with previous theory and research on both creativity and downsizing, and given that the downsizing was the most notable change occurring in this organization during this time, our confidence in attributing these results to the downsizing is bolstered. Moreover, our correlational patterns and, in particular, our regression results suggest that it was indeed anticipated downsizing and downsizing-related changes in work group stability that accounted for many of the work environment changes.

There are other limitations. Because this study was conducted in only one company, conceptual replications in other organizations will be required before firm conclusions can be drawn. Moreover, the low response rate for wave 2 is of concern, even though the wave 2 results do generally fit within the trajectory from wave 1 through wave 3 . In addition, results on the levels of downsizing and work group stability experienced must be interpreted cautiously, because they were obtained from self-reported measures and not from objective departmental data. Similarly, because the creativity measure was also based on self-reports, it would be desirable in future research to have additional external measures of creativity, such as the expert ratings used in earlier research linking the work environment to creativity (Amabile et al., 1996).

This study supports previous findings in several ways, but it also goes well beyond those findings. In the major previous empirical study of the possible impact of downsizing on innovation, Dougherty and Bowman (1995) examined changes at the organizational level-problem solving in product conceptualization, functional linkages, and strategic linkages across the organization they studied. In the present study, we examined changes through the experiences and perceptions of individuals working in project teams. We found disruption in innovation activities at this level, just as Dougherty and Bowman (1995) found them at the strategic level. In another empirical study, Tombaugh and White (1990) obtained findings similar to ours on work group disruptions. We have been able to go beyond these previous studies in both the scope of changes examined and the level of detail uncovered.

Importantly, our methodology embedded several advances recommended by previous downsizing researchers (e.g., Brockner, 1988; Tombaugh \& White, 1990): the use of uncontaminated predownsizing baseline data, examining both "high-downsizing" environments and "low-downsizing" environments within a large company, examining the time course of changes during a downsizing, and collecting data on group-level variables, such as work group stability. Moreover, by using surveys assessing the current work environment at various points in time, we were able to avoid at least some of the retrospective biases that might have entered into many previous field studies of downsizing.

Given that there is considerable consistency within our results and between these results and previous research, it is possible to identify several implications for management practice. This advice is congruent with much of that given by other researchers and theorists (e.g., Caplan \& Teese, 1997; Dougherty \& Bowman, 1995; O'Neill \& Lenn, 1995). First, and most obviously, it is important to do it right. Because the effects of downsizing on the work environment for creativity appear to be so consistently negative, managers must be sure that downsizing is a truly necessary course of action in the first place. Second, when it is not possible to maintain team stability, it may be helpful to undertake team-building efforts as soon as new groups are formed-especially if these are groups from which high levels of creativity are desired. Finally, organizational creativity will be less likely to suffer in a downsizing if the process is concluded in a timely manner and if a downsizing moratorium can be identified for some meaningful period of time afterward, thus minimizing the anticipation of downsizing.

After the mid-1990s, there was some suggestion in the business press that the downsizing trend was reversing. However, it is likely that, over time, economic circumstances will repeatedly trigger a series of corporate workforce contractions. Our study, along with the literature examining long-term economic outcomes (Cascio, 1993), suggests that corporate decision makers of the future should approach downsizing with great caution. The longterm negative effects of such actions on creativity and innovation may only retrigger the corporate woes that started the cycle in the first place.

\section{REFERENCES}

Amabile, T. M. 1983a. The social psychology of creativ. ity. New York: Springer-Verlag.

Amabile, T. M. 1983b. Social psychology of creativity: A componential conceptualization. Journal of Personality and Social Psychology, 45: 357-377.

Amabile, T. M. 1988. A model of creativity and innovation in organizations. In B. M. Staw \& L. L. Cummings (Eds.), Research in organizational behavior, vol. 10: 123-167. Greenwich, CT: JAI.

Amabile, T. M. 1995. KEYS: Assessing the Climate for Creativity. Greensboro, NC: Center for Creative Leadership. 
Amabile, T. M. 1996. Creativity in context: Update to the social psychology of creativity. Boulder, $\mathrm{CO}$ : Westview.

Amabile, T. M. 1997. Motivating creativity in organizations: On doing what you love and loving what you do. California Management Review, 40(1): 39-58.

Amabile, T. M., Burnside, R. M., \& Gryskiewicz, S. S. 1995. User's guide for KEYS: Assessing the Climate for Creativity. Greensboro, NC: Center for Creative Leadership.

Amabile, T. M., Conti, R., Coon, H., Lazenby, J., \& Herron, M. 1996. Assessing the work environment for creativity. Academy of Management Journal, 39: 1154-1184.

Amabile, T. M., \& Gryskiewicz, N. 1989. The creative environment scales: The work environment inventory. Creativity Research Journal, 2: 231-254.

Baumeister, R. F., \& Leary, M. R. 1995. The need to belong: Desire for interpersonal attachments as a fundamental human motivation. Psychological Bulletin, 117: 497-529.

Billings, R. S., Milburn, T. W., \& Shaalman, M. L. 1980. A model of crisis perception: A theoretical and empirical analysis. Administrative Science Quarterly, 25: 300-316.

Brockner, J. 1988. The effects of work layoffs on survivors: Research, theory, and practice. In B. M. Staw \& L. L. Cummings (Eds.), Research in organizational behavior, vol. 10: 213-255. Greenwich, CT: JAI Press.

Brockner, J., Davy, J., \& Carter, C. 1985. Layoffs, selfesteem, and survivor guilt: Motivational, affective, and attitudinal consequences, Organizational Behavior and Human Decision Processes, 36: 229244.

Brockner, J., Greenberg, J., Brockner, A., Bortz, J., Davy, J., \& Carter, C. 1986. Layoffs, equity theory, and work performance: Further evidence of the impact of survivor guilt. Academy of Management Journal, 29: $373-384$

Brockner, J., Grover, S., Reed, T., DeWitt, R., \& O'Malley, M. 1987. Survivors' reactions to layoffs: We get by with a little help for our friends. Administrative Science Quarterly, 32: 526-541.

Brockner, J., Wiesenfeld, B. M., Reed, T., Grover, S., \& Martin, C. 1993. Interactive effect of job content and context on the reactions of layoff survivors. Journal of Personality and Social Psychology, 64: 187-197.

Buch, K., \& Aldridge, J. 1991. O.D. under conditions of organizational decline. Organization Development Journal, 9(1): 1-5.

Cameron, K., Whetten, D., \& Kim, M. 1987. Organizational dysfunctions of decline. Academy of Management Journal, 30: 126-138.

Cameron, K. S., Sutton, R. I., \& Whetton, D. A. (Eds.). 1988. Readings in organizational decline: Frame- works, research and prescriptions. Cambridge, MA: Ballinger.

Caplan, G., \& Teese, M. 1997. Survivors: How to keep your best people on board after downsizing. Palo Alto, CA: Davies-Black.

Cascio, W. 1993. Downsizing: What do we know? What have we learned? Academy of Management Executive, $7(1)$ : 95-104.

D'Aveni, R. A. 1989. The aftermath of organizational decline: A longitudinal study of the strategic and managerial characteristics of declining firms. Academy of Management Journal, 32: 577-605.

D'Aveni, R. A., \& MacMillan, I. C. 1990. Crisis and the content of managerial communications: A study of the focus of attention of top managers in surviving and failing firms. Administrative Science Quarterly, 25: 634-657.

Dougherty, D., \& Bowman, E. 1995. The effects of organizational downsizing on product innovation. California Management Review, 37(4): 28-44.

Freeman, S. J., \& Cameron, K. S. 1993. Organizational downsizing: A convergence and reorientation framework. Organization Science, 4(1): 10-29.

Gilbert, D. T., Pinel, E. C., Wilson, T. D., \& Blumberg, S. J. 1997. Affective forecasting and the durability bias: The problem of the invisible shield. Paper presented at the Society for Experimental Social Psychology, Toronto.

Jensen, M. 1986. Agency costs of free cash flow, corporate finance, and takeovers. American Economic Review, 76: 323-329.

Judd, C. M., \& Kenny, D. A. 1981. Process analysis: Estimating mediation in treatment evaluations. Evaluation Review, 5: 602-619.

McKinley, W. 1993. Organizational decline and adaptation: Theoretical controversies. Organization Science, 4: 1-9.

Mone, M. A., McKinley, W., \& Barker, V. L. 1998. Organizational decline and innovation: A contingency framework. Academy of Management Review, 23: 115-132.

Noer, D. M. 1993. Healing the wounds: Overcoming the trauma of layoffs and revitalizing downsized organizations. San Francisco: Jossey-Bass.

O'Neill, H. M., \& Lenn, D. J. 1995. Voices of survivors: Words that downsizing CEOs should hear. Academy of Management Executive, 9(4): 23-33.

Rosenblatt, Z., Rogers, K. S., \& Nord, W. R. 1993. Toward a political framework for flexible management of decline. Organization Science, 4: 76-91.

Smart, C., \& Vertinsky, I. 1984. Strategy and the environment: A study of corporate responses to crises. Strategic Management Journal, 5: 199-213.

Staw, B. M., Sandelands, L. E., \& Dutton, J. E. 1981. Threat-rigidity effects in organizational behavior: A 
multilevel analysis. Administrative Science Quarterly, 26: 501-524.

Tjosvold, D. 1984. Effects of crisis orientation on managers' approach to controversy in decision making. Academy of Management Journal, 27: 130-138.

Tombaugh, J. R., \& White, L. P. 1990. Downsizing: An empirical assessment of survivors' perceptions in a postlayoff environment. Organization Development Journal, 8(2): 32-43.

Van de Ven, A. H. 1986. Central problems in the management of innovation. Management Science, 32: 590-607.

Whetten, D. A. 1981. Organizational responses to scarcity: Exploring the obstacles to innovative approaches to retrenchment in education. Educational Administration Quarterly, 17(3): 80-97.
Woodman, R. W., Sawyer, J. E., \& Griffin, R. W. 1993. Toward a theory of organizational creativity. Academy of Management Review, 18: 293-321.

Teresa M. Amabile is the Class of 1954 Professor of Business Administration and Senior Associate Dean for Research at Harvard Business School. She received her $\mathrm{Ph} . D$. in psychology from Stanford University. Her current research interests focus on the impact of specific events on project team work environments, motivation, and creativity.

Regina Conti earned her Ph.D. in psychology at Brandeis University and is an assistant professor of psychology at Colgate University. Her current research investigates selfregulation processes, including the maintenance of intrinsic motivation, the prevention of procrastination, and the strengthening of willpower. 
Copyright of Academy of Management Journal is the property of Academy of Management and its content may not be copied or emailed to multiple sites or posted to a listserv without the copyright holder's express written permission. However, users may print, download, or email articles for individual use. 